\title{
MUITO ALÉM DE UM SIMPLES ROLEX: BREVES CONSIDERAÇÕES SOBRE A LEGITIMIDADE DA ALTA RELOJOARIA E SUA EXPRESSÃO MÁXIMA DE VALOR ENTRE AS ELITES PAULISTANAS
}

\author{
MUCHO MÁS ALLÁ DE UN SIMPLE ROLEX: BREVES CONSIDERACIONES SOBRE \\ LA LEGITIMIDAD DE LA ALTA RELOJERÍA Y SU EXPRESIÓN MÁXIMA DE \\ VALOR ENTRE LAS ELITES PAULISTANAS
}

\section{BEYOND A SIMPLE ROLEX: BRIEF CONSIDERATIONS ON THE LEGITIMACY OF HIGH WATCHMAKING AND ITS MAXIMUM EXPRESSION OF VALUE AMONG THE SÃO PAULO ELITES}

RESUMO: O artigo tem como principal objetivo refletir sobre a legitimidade da distinção social exercida pelas elites de São Paulo ao de posicionarem como consumidoras e apreciadoras de relógios de luxo. Esse objeto será demonstrado também como um item primordial para a distinção e pertencimento a grupos restritos, como principal expoente para a caracterização e a singularidade do gosto burguês e o conservadorismo observado como ethos das classes abastadas de São Paulo.

PALAVRAS-CHAVE: Alta relojoaria. São Paulo. Consumo.

RESUMEN: El artículo tiene como principal objetivo reflexionar sobre la legitimidad de la distinción social ejercida por las elites de San Pablo al de posicionar como consumidoras y apreciadoras de relojes de lujo. Este objeto se demostrará también como un elemento primordial para la distinción y pertenencia a grupos restringidos, como principal exponente para la caracterización y la singularidad del gusto burgués y el conservadurismo observado como ethos de las clases acomodadas de São Paulo.

PALABRAS CLAVE: Alta relojería. São Paulo. Consumo.

ABSTRACT: This article has as main objective to reflect on the legitimacy of the social distinction exercised by the elites of São Paulo and to position as consumers and lovers of luxury watches. This object will also be demonstrated as a primordial item for the distinction and belonging to restricted groups, as the main exponent for the characterization and the singularity of the bourgeois taste and the conservatism observed as ethos of the wealthy classes of São Paulo.

KEYWORDS: High watchmaking. São Paulo. Consumption.

${ }^{1}$ Universidade Estadual Paulista (UNESP), Araraquara - SP - Brasil. Graduando em Ciências Sociais. ORCID: <https://orcid.org/0000-0002-9280-2507>. E-mail: viniciusseravo@gmail.com 


\section{Introdução}

O presente ensaio tem como objetivo discorrer sobre a questão dos gostos, a interferência da cultura na forma de consumo das elites e sobre o papel do objeto - nesse caso, o relógio de luxo - como bem distintivo em um espaço de circulação restrito.

A partir do debate sobre A Distinção: Crítica social do julgamento, de Pierre Bourdieu, A vida social das coisas de Arjun Appadurai, O Mundo dos bens de Mary Douglas e fragmentos de outros autores - visualizaremos uma reflexão que confere o mundo do simbólico como norteador para as relações sociais entre homem, objeto e cultura, tornando o objeto recortado um expoente legítimo de distinção e pertencimento a restrita esfera de consumidores de relógios de luxo.

Tendo o mundo simbólico como o mais importante para a existência dessas estruturas de distinção social, a argumentação desse ensaio transmitirá a interpretação do autor acerca da legitimidade do consumo de determinadas peças e suas implicações para os processos de distinção implícitos ao pertencimento a uma elite específica.

\section{Desenvolvimento}

As condições específicas da perpetuação da distinção das elites e a efetivação de seu habitus em um novo momento histórico onde é plausível iniciar uma reflexão sobre a ressignificação simbólica na estrutura social vigente para compreender de forma profunda sua dimensão e seus novos mecanismos de permanência já é uma discussão que começa caminhar e ser observada por Sahlins. Quando em sua obra Ilhas de História, o autor observa a especificidade do resultado do contato ocorrido entre povo haitiano e os exploradores ingleses liderados pelo capitão inglês James Cook - essa sociedade haitiana, até então, não havia sido apresentada ao capitalismo ou não havia tido contato com essa forma de organização socioeconômica introduzida a eles pelos ingleses. Fica claro na obra do autor supracitado que houve a reformulação de uma série de comportamentos e que os indivíduos absorveram novos referenciais, novas simbologias e novas atitudes, após o evento do contato propriamente ocorrido.

A partir dessas observações, as relações de sujeito e objeto passaram a tomar um papel dualista central na formulação de teses e teorias acerca dos sistemas culturais e suas perpetuações. Como trabalhado em Appadurai, a definição do homem é totalmente coligada ao objeto e as relações de ambos implicam na limitação de pessoas e grupos. A extinção da pureza 
cultural dos nativos das ilhas pacíficas do Havaí observadas por Sahlins em Ilhas de História desenvolveu uma relação observada no sentido de caracterizar esses nativos - agora - através dos objetos os quais eles carregavam, o que, ainda assim, não implicou em uma narrativa sobre o falecimento ou o fim dessa categoria cultural, mas sim a criação de uma nova forma de conceituar esse novo momento da sociedade havaiana. Esse evento, ocorrido como exemplo dentro do recorte de Sahlins, pode ser usado nessa reflexão como norteador para observar a contemporaneidade das relações entre sujeitos e objetos; a importância atribuída para a caracterização e segmentação de relações; e, o papel fundamental que esses objetos exercem sobre os limites de grupos e pessoas dentro da sociedade e da esfera de circulação restrita onde transita o relógio de extremo luxo - nas palavras de Jean Castarède.

A relação presente entre as experiências de contato dos ingleses com as tribos haitianas no pacífico oriental tem a ver com a perpetuação das relações simbólicas e o constante ressignificar dos objetos distintivos nas sociedades modernas; este é trazido a partir da noção de que esses contatos proliferam e reproduzem uma nova forma de cultura e que, em todos os aspectos, se utilizam de bens legítimos para sua permanência e estada nas altas esferas. Tanto os modos de agir adotados pelos nativos como pelos ingleses refletem seus universos simbólicos distintos e, principalmente - como busca debater esse ensaio - as formas de trocas novas e inéditas. Os bens, objetos e as relações simbólicas estabelecidas por ambas as culturas ao redor dessas trocas elucidam a legitimidade das novas culturas formadas.

Poucas coisas se mantiveram resistentes ao tempo e as transformações do capitalismo moderno - ironicamente, as ferramentas de marcação de tempo são uma delas. Para discutir o bem de consumo abordado neste ensaio precisamos, primeiro, caracterizar o que é um relógio de luxo, onde está sua legitimidade dentro da esfera da alta relojoaria e como esse objeto obtém o status dessa categoria, além de refletir sobre seu papel dentro dos enfoques de consumo propostos pela antropóloga britânica Mary Douglas em sua obra $\mathbf{O}$ mundo dos bens: para uma antropologia do consumo. Esses três enfoques carregam consigo três justificativas simbólicas que posteriormente demonstram o consumo como uma prática pública.

O caráter artístico das confecções dessas peças confere a elas algumas das principais características para que os relógios sejam classificados como alta relojoaria ou não. As características e regimes de valor conferidos a esses objetos têm, além do capitalismo, um universo de referências e simbologias para a legitimação de seu preço, ou, valor social. Sua raridade no mercado, alta necessidade de trabalho para produção e emprego de materiais preciosos de valor agregado são características econômicas norteadoras para iniciar a precificação dessas peças. Para que possamos nutrir e estabelecer parâmetros para as análises 
de valor subjacentes, a obra do antropólogo indiano Arjun Appadurai, A vida social das coisas, trará uma nova dimensão para a discussão acerca de valor desses objetos. Assim sendo e, com o decorrer da obra, Appadurai aprofunda esse debate e demonstra que o valor econômico está na troca de sacrifícios, essa sendo a origem do valor econômico do objeto.

Iniciando toda essa caracterização, então, temos em primeiro lugar a necessidade de observar a esfera da alta relojoaria e seus atores para depois iniciarmos as discussões simbólicas dos objetos que transitam por essas esferas, seus compradores, colecionadores, entusiastas e fabricantes, além dos motivos das compras, baseado na estrutura cultural - aprofundando essa reflexão de estrutura, para imaginar a alta relojoaria como o mercado dos automóveis de luxo, tomemos como exemplo o que diz Castarède na obra "O Luxo. Os segredos dos objetos mais desejados do mundo". Para o economista francês, esse mercado dos automóveis tem como principais agentes Rolls-Royce, Bentley, Porsche, Jaguar, Ferrari e alguns modelos top de linha da Mercedes-Benz, que representam o círculo interno do luxo extremo, acessível a poucos. É no sentido desse círculo interno que é tomado como norteador para a estrutura cultural em que o sociólogo francês Pierre Bourdieu fará sua contribuição no sentido de justificar e demonstrar que essa forma de capital norteia, legitima e classifica a aquisição desses bens, embasados nos três enfoques de consumo de Douglas.

Em primeiro lugar, tomaremos como conceito para alta relojoaria a definição proposta pela Fondation de la Haute Horlogerie (FHH). O Conselho Cultural da Fundação de Alta Relojoaria desenvolveu um manifesto em que propõe princípios para que o termo "Alta Relojoaria" possa ser entendido com mais clareza. O documento não busca definir uma ciência exata, mas sim oferecer alguns conceitos para melhor orientação, tanto de consumidores, quanto de marcas e, no nosso caso, de estudiosos.

Para a FHH, o termo abrange, entre outros fatores, uma história centenária e ainda viva, uma cultura requintada e específica, a ética profissional, o conhecimento persistente do artesão e uma paixão ardente. A definição de um relógio proveniente dos valores da alta relojoaria, pesquisa, inovação, desenvolvimento e treinamento de novas gerações, também é expressa no manifesto. Para receber o título de "relógio fino", o produto deve respeitar os seguintes elementos: O movimento deve demonstrar um grau excepcional de conhecimento técnico. Deve ser desenhado, desenvolvido e manufaturado com os mais altos padrões de qualidade, autenticidade, confiabilidade e rastreabilidade. Deve demonstrar uso técnico de materiais nobres, raros, preciosos ou inovadores. Cada componente deve receber acabamento perfeito e a máxima atenção deve ser dada ao mais ínfimo detalhe. Deve possuir grande valor estético e seu exterior (caixa, mostrador e pulseira) deve demonstrar criatividade, originalidade, 
autenticidade e individualidade. Além disto, o manifesto também define um perímetro que deve acompanhar as entidades envolvidas na alta relojoaria, como as marcas, e os valores compartilhados por elas.

Para se compreender o consumo de altos relógios a reflexão a ser desenvolvida deve transpor os ideais economicistas neoclássicos que propõem uma teorização sobre valor atribuída somente ao utilitarismo, na racionalidade e na maximização de resultados oferecida pelo objeto. Deve-se, a partir da reflexão trazida por Douglas, analisar que, nessa esfera e para esses objetos, o consumo deixa de representar somente a satisfação racional das necessidades básicas e orgânicas, se instaurando sob um enfoque atribuído ao hedonismo desse consumo, distante de todos os moralismos implícitos a prática deste. A autora elucida também o consumo, além do enfoque aqui enviesado, como prática pública. Na interpretação argumentativa e no decorrer deste ensaio, o consumo como prática pública sintetiza a máxima expressão do habitus de consumo do indivíduo familiarizado com esse objeto. Segundo Bourdieu, em sua obra sobre a teoria da distinção social, o termo habitus é tanto social quanto individual e reflete o capital cultural incorporado - que pode ser herdado ou aprendido - do indivíduo consumidor desses bens.

O debate que norteia a obra de Bourdieu traz a objetividade do uso do bem contra sua realidade subjetiva, ou seja, analisando através da ótica do consumo público, um relógio pertencente a alta relojoaria se torna a expressão máxima de distinção do indivíduo perante a sociedade - essa distinção se dá na expressão do filtro estético ali contido, segregando o indivíduo da sociedade; a ação social de seu uso legitima sua compra e o reconhecimento do mesmo ocorre apenas por indivíduos que incorporaram um determinado capital cultural presente em uma instância de consagração, um campo erudito.

Para debater de forma mais aprofundada e dar continuidade ao pensamento de que o consumo transpõe a lógica neoclássica defendida pelos economistas, podemos observar ainda em Bourdieu que o consumo adquire formas de se caracterizar. Através da arte, o consumo cultural desses bens expressa o filtro estético do simbolismo legítimo contido em um relógio pertencente a alta relojoaria. Esse simbolismo legítimo tem consigo todo o universo simbólico disposto por aquela mercadoria.

Os perfis de consumidores desses produtos devem ser observados, primeiramente, na condição de os atores pertencerem às altas esferas sociais, detentores de uma significativa quantidade de capital econômico e de lugares de prestígio dentro do estrato social. Uma análise realizada pela socióloga brasileira Carolina Pulici acerca do perfil dos indivíduos pertencentes a esse perfil de classe mostrou que, em comum, as elites paulistanas detêm um gosto burguês 
absolutamente clássico e conservador, sem dar espaço para criações modernistas - desde a arquitetura, até as artes plásticas que esses entrevistados mantém em suas paredes.

Talvez, esse gosto conservador da elite paulistana auxilie a formulação de um gosto por alta relojoaria e legitime seu consumo - uma vez que essa escola relojoeira se baseia no tradicionalismo europeu do século XIX e em padrões clássicos de confecção e estética rigorosamente obedecidos.

A reflexão que proponho é observar que esses objetos, mesmo que por algumas esferas sociais já superados em função - assim como pelos economistas neoclássicos - mantém seu papel de artigos de distinção e de segregação por manter uma imobilidade artística, por sempre ser confeccionado por marcas e relojoeiros reconhecidos em suas tradições. As normas estabelecidas pela Fondation Heute Horlogerie para reconhecimento dessas peças expressam um perfil muito compartilhado pela elite paulistana.

Quando Pulici analisou o gosto estético por moradias e suas formas arquitetônicas, principalmente no Jardim América - espaço ocupado por essa classe social distinta na cidade de São Paulo - ficou claro que a manutenção do gosto clássico e histórico é modus operandis para habitação e, ir contra esse consenso, vai contra todo um gosto de classe - o gosto burguês.

Essa análise reafirma o conservadorismo - não só estético - de nossas elites. Suas relações com o artístico, com o belo, com o usável e até mesmo com o distintivo é norteado pelo tradicionalismo - estético, político e social. As elites reproduzem sempre os mesmos comportamentos e padrões, inspirados sempre nos mesmos referenciais simbólicos. Quando se diz de referências artísticas, a conversa se mantém.

\section{Considerações finais}

Como propus no início deste escrito, estabelecer uma relação entre a cultura, o consumo e as funções simbólicas do relógio de luxo como item de distinção social entre as elites se torna um pensamento que deve levar em consideração os gostos artísticos dessa parcela da população paulistana. Ter a alta relojoaria como vitrine para a expressão dessa simbologia é, após essa análise, referência importantíssima para esses grupos que mantém seus gostos restritos ao que Bourdieu chamou de "gosto burguês".

Esse objeto em especial traz consigo uma série de características que o legitima como um signo completo para esses abastados consumidores - o que pode explicar de perto a existência de diversas relojoarias tradicionais suíças em shoppings centers e espaços de 
consumo frequentados por esses consumidores. Além de serem objetos pouco voláteis esteticamente e por demandarem um trabalho artesanal, absolutamente qualificado, além de sua oferta ser muito restrita no mercado, o relógio fruto de artesãos pertencentes aos conselhos reconhecidos pelas instituições legítimas, se tornam um expoente máximo da distinção de um indivíduo dentro dos grupos restritos e abastados - sendo que esses reconhecem apenas seus padrões estéticos tradicionais.

Se a arte tem como seu principal motor a progressão - a apresentação chocante de um novo estilo contra os gostos incorporados pelos tradicionais consumidores - no recorte da alta relojoaria analisado, o objeto adotado não pode ter sido melhor expoente da expressão máxima do sinônimo do conservadorismo dessas elites consumidoras, confirmando assim a teoria da socióloga Carolina Pulici sobre o gosto burguês no Brasil. Em termos de alta relojoaria, temos então que a inovação artística adota um plano secundário para a confecção e apresentação dessas peças, ela, em outras palavras, respeita o gosto burguês e se adequa ao conservadorismo desse meio.

Sendo assim, por deter essas características e ainda requerer uma bagagem cultural e artística muito restrita de ser adquirida pelos apreciadores, colecionadores e consumidores, o objeto - relógio de luxo - se torna a expressão perfeita da distinção do gosto burguês, onde o conservadorismo em todas as esferas de alia ao conservadorismo da função do objeto acima da produção artística do mesmo.

\section{REFERÊNCIAS}

APPADURAI, Arjun. A vida social das coisas. 1 ed. Rio de Janeiro: EDUFF, 1988.

BOURDIEU, Pierre. A distinção: critica social do julgamento. 2 ed. Rio de Janeiro: Zouk, 2011.

CASTARÈDE, Jean. O luxo: Os segredos dos produtos mais desejados do mundo. 1 ed. São Paulo: Barcarolla, 2005.

CHRONO 24. Whatis haute horlogerie?. Disponível em: https://www.chrono24.com/magazine/what-is-haute-horlogerie-p_20847/\#gref. Acesso em: 20 nov. 2018.

DOUGLAS, Mary; ISHERWOOD, Baron. O mundo dos bens: para uma antropologia do consumo. 2 ed. Rio de Janeiro: UFRJ, 2006. 
DURAND, José Carlos. Arte, privilégio e distinção. Artes plásticas, arquitetura e classe dirigente no Brasil 1855/1985. São Paulo/Perspectivas EDUSP, São Paulo, v. 1, n. 1, p. 280, jun. 1983.

FONDATION DE LA HAUTE HORLOGERIE. The fondation. Disponível em: https://www.hautehorlogerie.org/en/the-foundation/. Acesso em: 20 nov. 2018.

PULICI, Carolina. Preferências e aversões estéticas das classes altas de São Paulo. Novos Estudos, São Paulo, v. 1, n. 91, p. 123-139, nov. 2011.

SAHLINS, Marshall. Ilhas de História. 2 ed. Rio de Janeiro: Zahar, 2011.

WOLFF, Silvia Ferreira Santos. Jardim América: o primeiro bairro-jardim de São Paulo e sua arquitetura. Imprensa Oficial do Estado, São Paulo, v. 1, n. 1, p. 190, fev. 2001.

\section{Como referenciar este artigo}

SERAVO, Vinicius. Muito além de um simples Rolex: Breves considerações sobre a legitimidade da alta relojoaria e sua experiência máxima de valor entre as elites paulistanas. Rev. Sem Aspas, Araraquara, v.7, n.2, p. 259-266, jul./dez., 2018. E-ISSN: 2358-4238. DOI: 10.29373/sas.v7i2.12494

Submetido em: 25/01/2019

Aprovado em: 05/03/2019 